\title{
DA Gestão do CONHECIMENTO À WEBCIDAdANIA: UM CASO DE COLABORATIVIDADE, VALORES SOCIAIS E RESPONSABILIZAÇÃO EM REDE
}

\author{
FROM KNOWLEDGE MANAgEMENT TO WEB CITIZENSHIP: A CASE OF \\ COLABORATIVITY, SOCIAL VALUES AND ACCOUNTABILITY IN NETWORK.
}

\author{
Andrewes Pozeczek Koltermann ${ }^{1}$ \\ Liana Estela Merladete de Souza²
}

\section{Resumo}

Gerar conhecimento - e saber administrá-lo e difundi-lo - é uma questão de sobrevivência, mas também de desenvolvimento e, com vistas na eficácia de, sob uma ótica promissora, efetivar o funcionamento comunicacional colaborativo com o intuito do bem comum, contribuindo para a Gestão do Conhecimento por meio do adequado e inovador uso das ferramentas de Tecnologia da Informação e do alinhamento estratégico, esse retoma, nas seguintes páginas, as relações para a viabilização da Gestão do Conhecimento, mas, especialmente, a contextualização técnica e o conceito de colaboratividade envoltos num panorama de Administração Pública mais transparente a partir do caso de implantação do Observatório da Criminalidade e violência do Município de Bagé, localizado na microrregião da Campanha do Estado do Rio Grande do Sul.

Palavras-chave: Gestão do Conhecimento e Inovação, Tecnologia da Informação, e Comunicação Organizacional, Webcidadania e Governança.

\begin{abstract}
Creating knowledge - and learning how to manage and spread it - is a matter of survival, as well as development and intend to make the collaborative communication operation efficient aiming the common good, contributing to Knowledge Management through appropriate and innovative use of Information Technology tools and strategic alignment. This, retakes in the following pages the relations for the viability of knowledge management, but especially the technical context and the concept of collaboration wrapped in a more transparent public administration perspective from the case of the Crime and Violence Observatory implementation in the town of Bage, located in the microregion of Campanha in the State of Rio Grande do Sul.
\end{abstract}

Keywords: Knowledge Management and Innovation, Information Technology and Organizational Communication, Web citizenship and Governance.

\footnotetext{
${ }^{1}$ Mestrando no Programa de Pós-Graduação em Tecnologias Educacionais em Rede da Universidade Federal de Santa Maria (UFSM); Gerente de Projetos e Coordenador do Núcleo de Estudos em Webcidadania da Faculdade de Direito de Santa Maria (FADISMA). E-mail: apk@doisac.com

2 MBA em Gestão de Negócios pelo Centro Universitário Franciscano (Unifra); Coordenadora de Comunicação e Coordenadora do Núcleo de Estudos em Webcidadania da Faculdade de Direito de Santa Maria (FADISMA). E-mail: liana@doisac.com
} 


\section{INTRODUÇÃO}

As organizações, sejam elas públicas ou privadas, constituem uma parte integrante da vida das pessoas. Desde o nascimento até a morte, o indivíduo se depara com um imenso contingente de organizações. Essas apresentaram, ao longo de suas histórias e, de acordo com as suas trajetórias de cultura organizacional, diferentes enfoques na Administração.

Num contexto de Administração Pública Municipal, colocando uma Prefeitura como objeto de atenção, não é diferente. As organizações contemporâneas, inclusive na Gestão Pública, enfrentam ambientes extremamente dinâmicos, nos quais entre os pontos de debate aparecem as novas perspectivas de interação com os agentes disseminadores da plataforma de governo, das pastas governamentais (Segurança, Saúde, Trânsito, Cultura, Turismo, Educação etc.) e a sociedade. Isso levando em conta o cenário da Comunicação Organizacional e seu latente Planejamento Estratégico e, por conseguinte, a evolução tecnológica constante.

Fato é que depois da "Teoria das Máquinas", quando os aspectos construtivos do âmbito organizacional eram a prioridade e onde o foco na estrutura em si garantia a eficiência das partes envolvidas e, quando só se pensava no trabalhador enquanto uma máquina para o alcance de metas, observou-se mais, seja nos referidos âmbitos privados ou públicos.

Hoje, as inovações tecnológicas e o conseguinte avanço da informática permitem a redefinição de conceitos administrativos e colocam o elemento humano na posição de maior ativo de uma organização, a partir de seu conhecimento e complementariedade de competências.

Mas, nesse contexto, as tecnologias da informação conferem, aos recursos humanos de toda e qualquer organização que vislumbre o aperfeiçoamento de seu quadro e benefícios perante micro e macroambiente onde atuam, vantagens ao esforço humano e qualidade à comunicação estabelecida entre colegas, entre setores e entre níveis da pirâmide organizacional.

Gerar conhecimento - e saber administrá-lo e difundi-lo - é uma questão de sobrevivência, mas também de desenvolvimento e, com vistas na eficácia de, sob uma ótica promissora, efetivar o funcionamento comunicacional colaborativo com o intuito do bem comum, contribuindo para a gestão do conhecimento por meio do adequado e inovador uso das ferramentas de Tecnologia da Informação e do alinhamento estratégico, esse retoma, nas seguintes páginas, uma relação para a viabilização da gestão do conhecimento, mas especialmente a contextualização técnica e o conceito de colaboratividade envoltos num panorama de Administração Pública mais transparente 
a partir do caso de implantação do Observatório da Criminalidade e violência do Município de Bagé, localizado na microrregião da Campanha do Estado do Rio Grande do Sul.

Criação essa que não é apenas um ato solene, mas um marco na história do município em questão, representando muito mais que uma proposta, mas uma ação efetiva em prol de uma Segurança mais cidadã.

Bagé reafirma o seu compromisso com um futuro focado na importância da sensibilização e da formação permanente para a prevenção e erradicação da violência e criminalidade.

Mas também se alicerça no fato de que hoje são também as ferramentas digitais que invertem o eixo da participação na vida pública: de simples receptores das mensagens, noticiários, repercussões, os cidadãos passam a ter voz ativa e mais que isso: fomentam a transformação. E, os agentes de Segurança, dos mais diversos segmentos, passam a contar com instrumento qualificado para a contribuição no aconselhamento para a tomada de decisões em prol do desenvolvimento, da qualidade de vida e do bem-estar da população.

Buscando, nesse sentido, responder como podem se inter-relacionar os segmentos Tecnologia da Informação, Comunicação Organizacional, Webcidadania, Governança e Planejamento Estratégico de modo a gerar conhecimento, o mesmo contempla um pouco sobre o conceito de Conhecimento; da Tecnologia da Informação, da Comunicação e Planejamento no Contexto Organizacional; a viabilização do processo de Gestão do Conhecimento e; o consequente lugar da Governança e da Webcidadania, a partir da comunicação como direito do cidadão, na Administração Pública Transparente e Interativa.

\section{CONHECIMENTO: A VIABILIZAÇÃO}

A filosofia conta, conforme Nonaka \& Takeuchi (1997), que foi de Platão, discípulo de Sócrates, a definição que tomamos como boa por séculos: "crença verdadeira justificada". Passado algum tempo, segundo os autores, deixamos de jogar as nossas fichas na justificação e passamos a nos preocupar em desenvolver teorias que não mais apostassem em justificações, mas nas causas da produção da crença.

De uma evolução marcada por acharmos conhecer na medida em que em algo acreditássemos, passamos de verdade objetiva a variações subjetivas e, já há algum tempo, a literatura aponta que para falar em conhecimento, é indispensável falar em informação. Isso porque, segundo Borges (1995) conhecer, de os mais remotos tempos para cá, é emaranhar-se em códigos e preocupar-se em decifrá-los e, o que se observa nisso é um processo comunicativo. 
Informações oriundas daí se tornaram, independente de filosofia ou tempo, construção de conhecimento. Formas, intencionalidade e viabilização para tanto compõem a discussão de outros estudos e o que fica, na maior parte deles, é que a presença de tudo aquilo que se procura conhecer é indefinitivamente adiada, pois conhecimento não é simplesmente compreender a realidade retendo informações, mas utilizar-se dessas para, sempre, avançar rumo ao novo, assim como no Observatório, foco deste, que retendo algumas informações discutirá constantemente uma nova forma de não só encarar, mas de gerar e gerir conhecimento. E, por conseguinte, decisões estratégicas.

O fato, de acordo com Gregolin \& Tarapanoff (2001), é que planejamento, administração e tomada de decisão nas organizações, atualmente e dentro do contexto da nova ordem mundial, econômica e social, tendo a informação como principal recurso, têm, em uma gestão acerca do conhecimento, a oportunidade de concretizarem-se no mercado competitivo. E, transpondo para a realidade deste, de consolidar-se na interação em prol do desenvolvimento.

\section{TECNOLOGIA DA INFORMAÇÃO, COMUNICAÇÃO E PLANEJAMENTO NO CONTEXTO ORGANIZACIONAL}

O conceito de Tecnologia da Informação (TI) é mais abrangente do que os de processamento de dados, sistemas de informação, engenharia de software, informática ou de conjuntos de hardware e software. Sabe-se, hoje, que ele envolve, ainda, aspectos que compreendem o elemento humano e o enfoque administrativo e organizacional.

A tecnologia, definida como aplicação de conhecimentos científicos e técnicos à concepção, desenvolvimento e fabricação de produtos, foi estendida a todas as atividades que provoquem melhoria ou mudança na produção de bens e serviços. E, por que não dizer, da qualidade, do bem-estar e da sensação de segurança?

Partindo daí, entende-se, segundo Marcovitch (1997), por tecnologias de informação não simples ferramentas, mas um complexo tecnológico que envolve computadores, softwares, redes de comunicação eletrônica públicas e privadas, rede digital de serviços, tecnologias de telecomunicação, protocolos de transmissão de dados e outros serviços.

Em relação ao assunto, Tapscott \& Coston (1995) salientam que a TI, apesar de ainda ser considerada por alguns um fenômeno externo que se impõe à organização, é uma questão natural e, é possível compreender, a partir dessa apreciação sobre o tema, que pensar em tecnologia e administração na mesma equação é caminhar rumo à evolução. 
Assim, uma vez que a organização internaliza novas tecnologias, especialmente, em termos de tecnologias de informação e telecomunicações, conforme os autores, estas passam a alterar sua própria estrutura de poder com crescente disseminação de informações e, passam a alterar, também, sua habilidade em desenvolver novos produtos ou serviços e atender a novos interesses.

Contudo, nenhuma aplicação de $\mathrm{Tl}$, considerada isoladamente, por mais sofisticada ou glamorosa que seja, pode manter uma vantagem, pois essa só pode ser obtida pela capacidade da empresa e/ou organização em explorar a TI de forma contínua. O fato é que o uso eficaz da TI e sua integração vão além da ideia de ferramenta de produtividade. É uma questão de consciência.

Fala-se, aí, portanto, não da inserção na era da informação, mas de administração de tecnologia da informação e da percepção de seu papel estratégico e impacto no âmbito organizacional. Morton (apud Marcovitch, 1997), enfatiza esse processo em cinco ângulos. Entre os principais, os afetos à implantação do Observatório:

1. As tecnologias de informação estão provocando profundas alterações na organização do processo de trabalho: quanto mais a organização é sustentada pelo conhecimento e organização, mais é afetada pelos avanços tecnológicos;

2. As tecnologias de informação viabilizam a integração entre as diversas unidades da gestão e além de suas fronteiras, tornando os limites entre organizações cada vez mais virtuais;

3. A introdução bem-sucedida das tecnologias de informação requer mudanças nas estratégias de gestão e na estrutura organizacional, o que pressupõe mudança na cultura organizacional.

Com isso, se percebe que se a tecnologia da informação é parte integrante do processo de transformação e que é necessário investir em inovações tecnológicas, utilizar sistemas de informações gerenciais, implementar processo de mudança organizacional, utilizar o conhecimento como recurso estratégico e capacitar as pessoas para adaptação à nova realidade.

Eis o desafio. Talvez, o maior deles quando se fala em prosperar em ambientes sedentos por melhorias. Porém, assumir o risco é uma questão de sensibilidade, flexibilidade e adaptabilidade acerca de mudanças e estímulo para não apenas caminhar no mesmo ritmo da evolução, mas para fazer parte de seu processo.

A questão é relacionar TI e comunicação. As facilidades e possibilidades oferecidas pelas ferramentas de gestão de conteúdo podem surpreender os gestores e mais: a união e o potencial das ferramentas de estreitamento de relações no que tange à comunicação interna às novas tecnologias da informação não só agregam valor a uma organização pública, mas constituem uma 
nova etapa no seu ciclo de vida, o da construção de conhecimento sob o princípio do bem comunicar e tomar de tomar decisões com base em dados e fatos fidedignos.

\section{COMUNICAÇÃO ORGANIZACIONAL: DO CONCEITO E ABRANGÊNCIA NA SOCIEDADE DA INFORMAÇÃO AO LUGAR DA GOVERNANÇA E DA WEBCIDADANIA}

Com a evolução das organizações no que tange à redefinição dos conceitos administrativos, as atividades em comunicação, que eram, antigamente, percebidas e desenvolvidas apenas na edição de simples publicações empresariais e em muito pouco de assessoria de imprensa e marketing, ganharam - e continuam a ganhar de forma vertiginosa - um novo espaço que consolida a sociedade, e a tão falada, há algum tempo, a era da informação, que cede e/ou divide espaço com a era da colaboratividade.

A comunicação organizacional, que abrange todas as formas de comunicação utilizadas pela organização para relacionar-se e interagir com seus públicos, é hoje encarada como um processo integrado do qual nenhuma organização moderna pode abrir mão.

Deixando o tradicionalismo de lado, quando falar em comunicação era essencialmente falar em transferência de informações, a comunicação organizacional e suas modalidades lançam mão, hoje, de uma articulação e de um processo sistêmico que, conforme Kunsch (1999), viabilizam toda a interação possível entre a organização e seus colaboradores por meio de metodologias e técnicas de comunicação institucional que remetem à construção interna e externa da credibilidade.

Nesse cenário, na Gestão Pública, onde uma visão que promova o equilíbrio e o desenvolvimento constante entre gestor e sociedade na mesma equação é o ideal, se faz necessária uma comunicação que passe, igualmente, por todos os níveis da pirâmide também. E é aí que se encaixa a comunicação colaborativa, mas, essencial e fundamentalmente, a Governança e a Webcidadania. E, amarrando tudo isso, o Planejamento Estratégico.

Certamente, este último, definido, basicamente, como metodologia científica para construir a realidade é, hoje, uma importante ferramenta.

E enquadrada a um planejamento formal, a tecnologia da informação, se adaptada para gerar e gerir conhecimento em âmbito organizacional, corresponde não só à consciência de alinhamento estratégico, mas da tecnologia integrada à inteligência. A convergência da infraestrutura tecnológica, quando pensada sistematicamente, não só aniquila distâncias, mas determina perfis e resultados. 
Em linhas gerais, viabilizar a gestão do conhecimento não é apenas avançar em uma determinada área, mas objetivar ocupar um território. Se o cenário organizacional dos dias de hoje representa complexidade e, ainda, uma série de fenômenos econômicos e sociais, faz-se necessário o impulso não só do desejo de gerar e gerir conhecimento, mas da tecnologia da informação.

Conforme Rezende (2003), é através dessa e de um adequado e bem delimitado plano de comunicação, que o conhecimento pode transformar-se num valioso recurso estratégico. $\mathrm{Na}$ Gestão Pública, é o conhecimento, quando aliado ao planejamento, que faz toda a diferença.

O que é necessário saber, para tanto, é como realmente trabalhar com ele. Conforme Dombrowski (2006), estudos de pesquisas anteriores apontam que a Gestão do Conhecimento tende a apresentar resultados mais eficientes e eficazes quando trabalhada a partir da diferença entre dado, informação e conhecimento. Partindo do pressuposto de que a capacidade de transformar dados em conhecimento e de utilizá-los em proveito da organização torna, segundo Probst, Raub \& Romhardt (2002), o colaborador um agente primário do conhecimento, a ideia se comprova.

A exemplo disso, encontra-se, a partir da literatura de Tiwana (2002), Bhatt (2001) e Winkler e Mandl (2005), um conceito único para esses abrangentes constituintes do conhecimento. Tomando, assim, para dado, a definição de apresentação bruta de caracteres, na forma de letras e símbolos, sem nenhum significado por si só; para informação, o conjunto organizado de dados brutos, que servem para atingir um determinado fim e; para conhecimento, a informação provida de sentido, aplicada dentro de um contexto próprio, com a finalidade de atingir um ou mais objetivos, percebe-se que o colaborador, se munido dos três, poderá desencadear significativa vitalidade no processo de implantação do conhecimento.

Ao agregar experiências individuais, crenças, valores, bem como intuição, reflexão, bom senso, planejamento, habilidade de decidir e capacidade de discernimento é possível, como aponta a figura 01, enquadrar-se em um novo sistema, onde toda e qualquer organização disposta a investir recursos e esforços na construção do conhecimento por toda e por entre a sua pirâmide organizacional, especificará atitudes acerca da aplicação correta e adequada daqueles dados e informações disponíveis. 
Figura 01: Processo de Criação de Conhecimento por Silva \& Neves (2003)

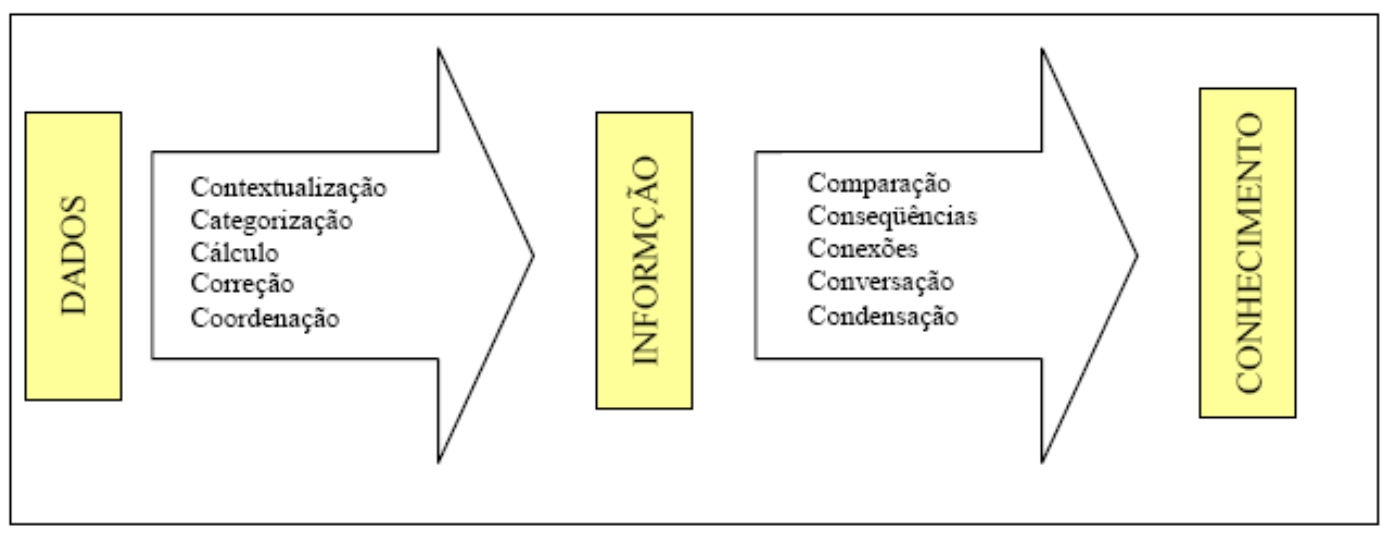

O fato é que não param por aí os estudos e as pesquisas acerca do conhecimento, já que o mesmo é, atualmente, encarado como o maior ativo de uma organização sob a definição de capital intangível.

Nesse cenário, se descobre que para obter total êxito no que se refere à administração da tecnologia da informação diversas ações se fazem necessárias. E, aí se encaixa o reconhecimento do elemento humano que, por sua vez, entrelaça comunicação eficaz e fomento ao conhecimento.

É o caso das etapas iniciais da implantação do Observatório da Violência e Criminalidade de Bagé, que compreenderam o mapeamento dos índices de criminalidade e violência, o desenvolvimento de instrumentos de pesquisa, e o software específico, para monitoramento permanente da Segurança Pública local.

E, entre as etapas metodológicas, a qualificação e aperfeiçoamento da gestão pública municipal no campo da segurança foi ponto fundamental, que hoje está ainda mais disposta a compreender, incorporar e analisar ocorrências, em prol de soluções eficazes, assimilando o papel da sociedade na Política de Segurança Pública.

Daí, percebe-se que todo o processo de planejamento estratégico, consolidadamente embasado na definição de visão de futuro, metas, objetivos e estratégias de ação depende, prioritariamente daqueles que concretizam e alimentam o capital intelectual organizacional: o elemento humano.

Este, por sua vez, caracteriza, também, a Governança de TI, um conjunto de práticas, padrões assumidos pelos executivos, gestores e técnicos envolvidos nesse processo, com o objetivo de garantir controles efetivos, ampliar os processos de segurança e desempenho. 
Se a sociedade do século XXI está conectada, ou melhor, é conectada, esse fato e/ou tendência foi acompanhado pela Prefeitura em questão e, essencialmente, pela Faculdade de Direito de Santa Maria, como gestora e executora do processo. A relação e a potencial ligação do Direito com a tecnologia promovem a análise e discussão de dados/casos a partir do elemento virtual, conhecendo e reconhecendo o Direito, seus instrumentos e seu potencial de solução num patamar de visibilidade, fomentando articulação, mobilização e o bem comum.

Mais, mais que isso. Peruzzo (2005) dizia que, no nível do discurso, várias entidades, estudiosos e ativistas têm se posicionando publicamente a favor do direito à comunicação, tomando-o como um mecanismo de se efetivar a democratização dos meios de comunicação.

Se, segundo a autora, no que concerne ao entendimento do que vem a ser direito à comunicação, tradicionalmente as abordagens teóricas tendem a enfocá-lo sob o ângulo do direito ao acesso à informação ou como direito à liberdade de informação e de expressão; se tal concepção vem sendo renovada ao incluir a dimensão do direito à comunicação como acesso ao poder de comunicar, não seria a hora de, não só no universo corporativo e de organizações nãogovernamentais e/ou mesmo do espaço e da representação dos movimentos sociais, mas via esfera pública propiciar essa comunicação? E mais: a partir da gestão do conhecimento que essa permite imprimir ações efetivamente relacionadas a demandas fidedignas da população?

\section{CONSIDERAÇÕES FINAIS}

A criação do Observatório da Violência e da Criminalidade de Bagé, município da Microrregião da Campanha Meridional do Estado do Rio Grande do Sul, não é apenas um ato solene, mas um marco na história do município. Representa muito mais que uma proposta, mas uma ação efetiva em prol de uma segurança mais cidadã.

O ato de criação foi firmado pelo Diretor da Faculdade de Direito de Santa Maria (FADISMA), Eduardo de Assis Brasil Rocha, e pelo prefeito, Luís Eduardo Dudu Colombo dos Santos, em janeiro de 2013. De lá para cá, Bagé reafirma o seu compromisso com um futuro focado na importância da sensibilização e da formação permanente para a prevenção e erradicação da violência e criminalidade.

A oportunidade é oriunda do Ministério da Justiça e se deu por meio do Programa Nacional de Segurança Pública com Cidadania (Pronasci). O Observatório contou, no estágio de implantação, com atividades de planejamento, gestão e orientação para execução sob a responsabilidade do Núcleo de Segurança Cidadã da FADISMA e seu expertise em ensino, pesquisa e extensão. As 
atividades de suporte contaram com a cooperação técnica e científica da Universidade da Região da Campanha (Urcamp) - Campus Bagé, e com o Instituto de Desenvolvimento Educacional do Alto Uruguai (IDEAU)

O Observatório é subordinado ao Gabinete de Gestão Integrada (GGI-M) e é, básica e fundamentalmente, utilizado para pesquisar a violência na cidade.

As etapas iniciais compreenderam o mapeamento dos índices de criminalidade e violência, o desenvolvimento de instrumentos de pesquisa, e software específico, para monitoramento permanente da segurança pública local. E, entre as etapas metodológicas, a qualificação e aperfeiçoamento da gestão pública municipal no campo da segurança foi ponto fundamental, que hoje está ainda mais disposta a compreender, incorporar e analisar ocorrências, em prol de soluções eficazes, assimilando o papel da sociedade na Política de Segurança Pública.

No quesito desenvolvimento de software específico, sabendo que o principal papel da tecnologia da informação na gestão do conhecimento, quando tomada sob a perspectiva da comunicação organizacional, é ampliar o alcance e acelerar a velocidade de transferência de conhecimento, disponibilizá-lo de forma compartilhada com vistas na construção de bases inteligentes é a essência para a viabilização de metas eficientes e eficazes no panorama da Gestão Pública, promovendo o Direito à transparência, colocando em voga à interação, mas também os valores sociais e à responsabilização.

O papel do observatório num contexto que traz a Webcidadania como um dos protagonistas dado a sua cultura de colaboratividade e generosidade, é viabilizar, de uma maneira sistemática, a congregação de diversas metodologias em prol da eficiente gestão do conhecimento, incutindo em sua cultura, a prerrogativa de aprendizado contínuo, com base na tenacidade e análise e avaliação constantes.

O trabalho de TI, por trás de um minucioso trabalho de pesquisa desenvolvido pelo Núcleo de Segurança Cidadã da FADISMA, teve um compromisso objetivo, focado e centrado num escopochave em prol da gestão da informação e da inovação. A leitura técnica do conjunto de estratégias e a identificação da tradução das necessidades informacionais em mapa e ambiente web é o principal ponto. Em resumo, tecnicamente, foi preciso estabelecer ativos correspondentes ao conjunto de estratégias pensadas pelos coordenadores da pesquisa para criar, adquirir, compartilhar e traduzir dados em conhecimento e ação, como prevê o NUSEC, reflexo da execução, apuração, análise e diagnóstico do panorama atual na seara de segurança e auxilio 
organizacional em prol de políticas públicas e sociais que consolidem e/ou somem a proposta do Observatório.

É a grande modificação da economia informacional em rede na esfera pública a partir de uma ferramenta que promove maior atividade, interação e envolvimento dos agentes de segurança, mas também a prestação de contas à sociedade, consolidando o protagonismo de Bagé na região da campanha no que tange à esfera pública virtual.

\section{REFERÊNCIAS BIBLIOGRÁFICAS}

BERALDI, Luiz Carlos. Tecnologia da Informação integrada à Inteligência Empresarial: Alinhamento Estratégico e Análise da Prática nas Organizações. In: FAE Business School. São Paulo: no 5, 2003.

BHATT, Ganesh D. Knowledge management in organizations: examining the interaction between technologies, techniques, and people. Journal of Knowledge Management, v. 5, n.1, p. 68-75, 2001.

BORGES. Mônica Erichsen Nassif. A Informação como recurso gerencial das organizações na sociedade do conhecimento. Ciência da Informação, Volume 24, número 2, 1995.

DOMBROWSKI, Cristiane Alves. Gestão do Conhecimento em Parques Tecnológicos: Um Estudo de Caso Único. Dissertação Mestrado em Administração e Negócios da Pontifícia Universidade Católica do Rio Grande Do Sul. Porto Alegre: 2006.

GREGOLIN, José Ângelo R. \& TARAPANOFF. Kira. Inteligência organizacional e competitiva. Brasília: Editora UnB, 2001. 344p.

KAPLAN, R. S.; NORTON, D. P.; A Estratégia em Ação - Balanced Scorecard. Rio de Janeiro: Campus, 1997.

Organização Orientada para a Estratégia: como as empresas que adotam o Balanced Scorecard prosperam no novo ambiente de negócios. Rio de Janeiro: Campus, 2000.

LUPETTI, Marcélia. Planejamento de Comunicação. São Paulo: Editora Futura, 2000.

MARCOVITCH, Jacques. Tecnologia da Informação e estratégia empresarial. São Paulo: Futura, 1997.

NONAKA, Ikujiro; TAKEUCHI, Hirotaka. Criação de conhecimento na empresa. Rio de Janeiro: Campus, 1997.

(2003) Criação de conhecimento na empresa: como as empresas japonesas geram a dinâmica da inovação. (11. ed.) Rio de Janeiro: Campus.

PERUZZO, Cicília M. Krohling. Direito a comunicação comunitária, participação popular e cidadania. Revista Latinoamericana de Ciencias de La comunicación. Ano II. № 3, 2005. Disponível em http://www.alaic.net/revistaalaic/index.php/alaic/article/view/145/16. Acesso em 05/04/2015. 
PROBST, G.; RAUB, S.; ROMHARDT, Kai. Gestão do Conhecimento: os elementos constitutivos de sucesso. Porto Alegre: Bookman, 2002.

REZENDE, Yara. Natura Cosméticos: conhecendo pessoas e gerando inovação. In: TERRA, José Cláudio Cyrineu (Org.). Gestão do conhecimento e e-learning na prática. Rio de Janeiro: Campus, 2003

SOUZA \& FOSSÁ, Liana Estela Merladete de. \& Maria Ivete Trevisan. Comunicando com Relações Públicas: Uma proposta de atuação estratégica para o fortalecimento do comprometimento organizacional. UNISINOS: UNIrevista, vol1, no3, julho de 2006.

TAPSCOTT, Don; CASTON, Art. Mudança de Paradigma. São Paulo: Makron Book, 1995.

TIWANA, Amrit. Knowledge Management Toolkit. Orchestrating IT, strategy, and knowledge platforms. 2. ed. Prentice Hall PTR, EUA: 2002.

TORQUATO, Gaudêncio. Tratado de Comunicação Organizacional e Política. São Paulo: Editora Thomson Learning, 2002.

Trabalho enviado em 12 de maio de 2015.

Aceito em 02 de agosto de 2015. 